\title{
The Impact of Learning Curve on Flap Thickness Outcome in Femtosecond Laser-assisted Laser In Situ Keratomileusis Performed with New LenSx Dual Platform
}

\author{
Bilgehan Sezgin Asena' ${ }^{1}$ Oya Donmez ${ }^{2}$ \\ ${ }^{I}$ Department of Ophthalmology, Kaskaloglu Eye Hospital, Izmir, Turkey \\ ${ }^{2}$ Department of Ophthalmology, Tinaztepe Galen Hospital, Izmir, Turkey
}

\begin{abstract}
Purpose: To evaluate the effect of learning curve on flap thickness (FT) outcome in femtosecond (FS) laser-assisted laser in situ keratomileusis (LASIK) operation for myopia performed with recently introduced LenSx dual platform using curved applanation cone.

Methods: Seventy eyes of 36 patients with myopia or myopic astigmatism operated with FS laser-assisted LASIK with recently introduced LenSx dual platform were evaluated in this retrospective study. Operations were divided into two groups: first 20 operations ( 20 eyes of 10 patients) and next 50 operations (50 eyes of 26 patients). Data on patient demographics, preoperative and postoperative keratometric and aberrometric parameters, and FT related outcome, including mean central FT, mean total FT, intra-FT range, and FT homogeneity were compared in study groups.

Results: Except for significantly lower preoperative steepest keratometry values in the next 50 operations versus first 20 operations ( $p=0.033$ ), no significant difference was noted between study groups in terms of preoperative and postoperative parameters. When compared to first 20 operations, next 50 operations were associated with significantly higher values for mean central FT (median, $123 \mu \mathrm{m}$ vs. $114 \mu \mathrm{m} ; p=0.007$ ) and mean total FT (median, $123 \mu \mathrm{m}$ vs. $113 \mu \mathrm{m} ; p=0.015$ ), whereas significantly lower intra-FT range (median, $4.0 \mu \mathrm{m}$ vs. $4.5 \mu \mathrm{m} ; p=0.003$ ).

Conclusions: In conclusion, our findings related to FS laser-assisted LASIK surgery for myopia with new LenSx dual platform using curved applanation cone revealed significant impact of learning curve on the corneal FT outcome in terms of closer FT to the intended value and lower intra-flap range.
\end{abstract}

Key Words: Laser in situ keratomileusis, LenSx, Learning curve, Surgical flap

Received: September 30, 2021 Final revision: December 25, 2021 Accepted: December 30, 2021

Corresponding Author: Bilgehan Sezgin Asena, MD. Kaskaloglu Eye Hospital, 1400 Sokak No.10, Alsancak, Izmir 35220, Turkey. Tel: 90-532320-0898, Fax: 90-232-465-0506, E-mail: drbsezgin@yahoo.com
Laser in situ keratomileusis (LASIK) remains to be the most commonly used technique in refractive surgery for correction of ametropia [1-3]. LASIK flap creation, obtaining a flap of predictable thickness and morphology with minimum alteration in corneal biomechanics, is considered the most critical step of LASIK in terms of postoperative visual outcome of the whole procedure [3-5]. Thus, the 
technological evolution of flap creation has emerged from manually guided mechanical microkeratomes to automated microkeratomes, single-use microkeratomes, and most recently to femtosecond (FS) laser technology $[3,6,7]$.

In 2015, a new software program was installed to the original software of the LenSx FS laser (Alcon, Aliso Viejo, CA, USA) to perform LASIK flaps via the same FS laser previously used for cataract surgery. Thus, new FS laser platforms that are able to perform both corneal LASIK flaps and FS laser-assisted cataract surgery with a "onefor-all" approach have been developed. Some of these new "dual" FS lasers use a curved patient interface in the applanation cone. This theoretically allows for better approximation of the contour of the cornea, enabling an easier docking process while requiring less suction and minimizing corneal compression and distortion with less elevation in intraocular pressure (IOP), and it is therefore easier for the patient to maintain fixation while the suction ring is seated $[5,8]$.

Although the perceived benefits are promising in terms of good visual outcomes and acceptable flap thickness (FT) predictability, there is limited published evidence regarding the corneal flap morphology outcome of the dual LenSx FS laser (Alcon) device using curved applanation cone $[5,9]$. Indeed, the learning curve of surgeons and the lack of sufficient data on safety profiles of FS laser technology overall, not only for the new LenSx dual platform, are considered amongst the major barriers in use of FS lasers for LASIK in real-life clinical practice [10].

Notably, moistness status of the contact surface is of critical importance in using the curved applanation cone. If the cornea is too wet, there is a risk of thinner flap than planned since excess fluid at the interface can go up to suction loss. Therefore, it is required to remove excess fluid from the sclera before docking. However, in case of insufficient moisturization epithelial wrinkles may occur, which negatively impacts the focus of laser beams and flap quality $[5,11]$. Hence, although the transition is easy for existing FS laser-assisted LASIK surgeons, there is a short learning curve for optimization of the contact surface. We aimed to evaluate the effect of this learning curve on FT using the anterior segment optical coherence tomography, considered a reliable method for assessing FT parameters in LASIK for the cornea $[12,13]$. This study was therefore designed to evaluate the effect of learning curve on FT outcome in FS laser-assisted LASIK operation for myopia performed with recently introduced LenSx dual platform, LenSx ver. 2.31 (Alcon), using curved applanation cone.

\section{Materials Methods}

\section{Ethics statement}

The study was approved by the Institutional Ethics Committee of Izmir Tinaztepe University (No. IZTU 00122019) and was conducted in accordance with the ethical principles stated in the Declaration of Helsinki. Written informed consent was obtained from each subject following a detailed explanation of the objectives and protocol of the study.

\section{Study population}

Seventy eyes of 36 patients with myopia or myopic astigmatism who underwent FS laser-assisted LASIK between January 2019 and August 2019 in Kaskaloglu Eye Hospital were evaluated in this retrospective study. Operations were divided into two groups based on the time of operation: first 20 operations (the first 20 eyes of 10 patients) and next 50 operations (50 eyes of 26 patients). The surgery of first 20 eyes of 10 patients were performed under supervision during education to be eligible to perform FS laser-assisted LASIK surgery with curve applanation. That is why we divided the first 20 eyes of 10 patients as first cases which were performed under supervision.

Patients with myopia (up to 7.75 diopters [D]), with or without astigmatism (up to $4.00 \mathrm{D}$ ), with a preoperative corrected distance visual acuity of at least 0.63 (decimal notation) were included in the study. Presence of unstable refraction, previous refractive or other type of ocular surgery, topographic suspicion of keratoconus, and any ocular or systemic disease that could interfere with the wound-healing process were the exclusion criteria of the study.

\section{Study parameters}

Data on patient demographics (age, sex) and preoperative (manifest sphere D [D], cylinder [D], spherical equivalent [SE], flat keratometry reading [K1] and steep keratometry reading $[\mathrm{K} 2]$, mean keratometry, pachymetry $[\mu \mathrm{m}]$, 
planned FT $[\mu \mathrm{m}]$, flap diameter $[\mathrm{mm}]$ and optic zone) and postoperative (manifest sphere D [D], cylinder [D], SE, K1, $\mathrm{K} 2$, and mean keratometry) keratometric and aberrometric parameters were recorded in each patient. FT related outcome was evaluated based on mean central FT (MCFT), mean total FT (MTFT), intra-FT range and FT homogeneity (FTH).

\section{Keratometric and aberrometric analyses}

Scheimpflug imaging-based corneal tomography system (Oculus Pentacam; Oculus GmbH, Wetzlar, Germany) and placido-based corneal topography system (WaveLight Allegro Topolyzer; Alcon Laboratories, Fort Worth, TX, USA) were used to determine K1 (flat keratometric reading) and K2 (steep keratometric reading), Q value (corneal asphericity coefficient), and corneal aberrations which analyzed total aberrations, high order aberrations, vertical coma, horizontal coma, and spherical aberrations.

\section{Surgery and imaging analysis}

All surgeries were performed by the same surgeon (BSA) who was experienced in FS lasers with planar applanation. The flap was created with the LenSx FS laser. No patient had suction loss. The FS laser was programmed to a flap thickness of $120 \mu \mathrm{m}$ and a flap diameter of 9.0

Table 1. The femtosecond laser "programmed" flap parameters

\begin{tabular}{lc}
\hline Variable & Set at \\
\hline Flap parameters & \\
Diameter $(\mathrm{mm})$ & 9.0 \\
Thickness $(\mu \mathrm{m})$ & 120 \\
Energy $(\mu \mathrm{J})$ & 0.95 \\
Tang spot separation $(\mu \mathrm{m})$ & 7 \\
Radial spot separation $(\mu \mathrm{m})$ & 7 \\
Side cut parameters & \\
Hinge position $\left({ }^{\circ}\right)$ & 90 \\
Hinge angle $\left({ }^{\circ}\right)$ & 50 \\
Side cut angle $\left(^{\circ}\right)$ & 70 \\
Energy $(\mu \mathrm{J})$ & 2.20 \\
Spot separation $(\mu \mathrm{m})$ & 3 \\
Layer separation $(\mu \mathrm{m})$ & 2 \\
\hline
\end{tabular}

$\mathrm{mm}$ to with a $70^{\circ}$ angled side cut and a $50^{\circ}$ hinge angle (Table 1). In all cases, flaps were lifted with a parabolic shaped tip lifter (Rhein 08-16172; Katenai, Denville, NJ, USA) and the stromal ablations were performed with the same WaveLight EX500 excimer laser (Alcon), with an optical zone larger than or equal to the mesopic pupillary size, in all cases. For the hydration and to lay the flap back down, we use a multiport irrigator.

Imaging and measurement of the LASIK flaps were performed by high-speed anterior segment optical coherence tomography (Cirrus HD OCT 5000; Carl Zeiss Meditec, Dublin, CA, USA). FT was measured at three points in each horizontal image (center, $2 \mathrm{~mm}$ nasal, and temporal to the vertex) (Fig. 1). FT was measured at three points along the horizontal meridian passing through the corneal center. The corneal center was determined by the presence of high reflective artifacts while scanning for corneal apex. The flap was evaluated with a horizontal line scan measuring $20^{\circ}$ and FT was measured at three points: center, $2 \mathrm{~mm}$ nasal, and temporal to the vertex. The adjustments were done manually, and the readings were calculated accordingly based on the measuring tool of the device. Flaps were visible in all optical coherence tomography scans obtained 2 weeks postoperatively. FT related outcome was evaluated based on MCFT, MTFT (defined as the mean thickness value of all three FT points measured in the horizontal meridian of each flap), intra-FT range (defined as the difference between the thickest and thinnest points in each flap), and FTH (defined as the thickness difference between the two measurement points located $2 \mathrm{~mm}$ nasally and temporally from the corneal apex).

\section{Statistical analysis}

Statistical analysis was performed using the MedCalc ver. 12.7.7 (MedCalc Software, Ostend, Belgium). The normality of continuous variables was investigated by Shapiro-Wilk test. Categorical variables were assessed with chi-

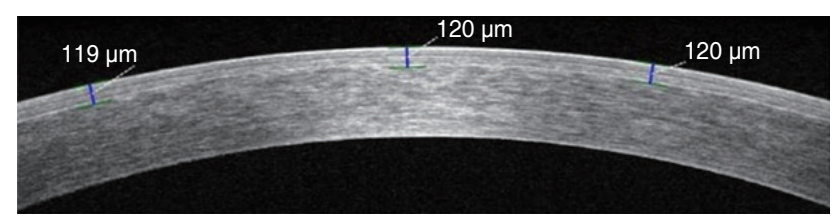

Fig. 1. Flap thickness measurement in three flap points through horizontal anterior segment optical coherence tomography. 
Table 2. Patient demographics and preoperative and postoperative keratometric and aberrometric parameters in study groups

\begin{tabular}{|c|c|c|c|}
\hline Patient demographic & First 20 operations $(n=10)$ & Next 50 operations $(n=26)$ & $p$-value* \\
\hline Age (yr) & & & 0.794 \\
\hline Mean $\pm \mathrm{SD}$ & $26.5 \pm 6.0$ & $26.9 \pm 8.1$ & \\
\hline Median (range) & $24.5(21.0$ to 40.0$)$ & 25 (20.0 to 55.0$)$ & \\
\hline Sex, n $(\%)$ & & & $0.711^{\dagger}$ \\
\hline Female & $4(40.0)$ & $14(53.8)$ & \\
\hline Male & $6(60.0)$ & $12(46.2)$ & \\
\hline Preoperative parameters & & & \\
\hline Manifest sphere D (D) & & & 0.804 \\
\hline Mean \pm SD & $-2.9 \pm 2.6$ & $-3 \pm 1.6$ & \\
\hline Median (range) & $-3.3(-7.5$ to 0.0$)$ & $-2.5(-7.8$ to 0.0$)$ & \\
\hline Cylinder (D) & & & 0.190 \\
\hline Mean \pm SD & $-1.4 \pm 1.2$ & $-0.9 \pm 0.8$ & \\
\hline Median (range) & $-1.3(-4.0$ to 0.0$)$ & $-0.8(-3.3$ to 0.0$)$ & \\
\hline SE (D) & & & 0.979 \\
\hline Mean \pm SD & $-3.5 \pm 2.2$ & $-3.4 \pm 1.7$ & \\
\hline Median (range) & $-3.6(-7.5$ to -0.9$)$ & $-2.9(-8.1$ to -1.0$)$ & \\
\hline K1 (D) & & & 0.208 \\
\hline Mean \pm SD & $43.4 \pm 1.9$ & $42.9 \pm 1.2$ & \\
\hline Median (range) & $43.1(39.8$ to 46.8$)$ & $42.8(41.3$ to 46.0$)$ & \\
\hline K2 (D) & & & 0.033 \\
\hline Mean \pm SD & $44.9 \pm 2.1$ & $44.1 \pm 1.3$ & \\
\hline Median (range) & $45.0(40.5$ to 49.0$)$ & $43.9(42.0$ to 47.8$)$ & \\
\hline Mean keratometry (D) & & & 0.064 \\
\hline Mean \pm SD & $44.2 \pm 1.9$ & $43.5 \pm 1.2$ & \\
\hline Median (range) & $43.8(40.1$ to 47.4$)$ & $43.2(41.6$ to 46.9$)$ & \\
\hline Pachymetry $(\mu \mathrm{m})$ & & & 0.424 \\
\hline Mean \pm SD & $561.0 \pm 28.5$ & $568.1 \pm 29.3$ & \\
\hline Median (range) & 554.5 (524.0 to 615.0$)$ & $559.0(525.0$ to 662.0$)$ & \\
\hline Planned flap thickness $(\mu \mathrm{m})$ & & & $>0.999$ \\
\hline Mean \pm SD & $120 \pm 0$ & $120 \pm 0$ & \\
\hline Median (range) & $120(120$ to 120$)$ & $120(120$ to 120$)$ & \\
\hline Flap diameter (mm) & & & 0.360 \\
\hline Mean \pm SD & $9.0 \pm 0.1$ & $9.0 \pm 0.1$ & \\
\hline Median (range) & $9.0(8.8$ to 9.1$)$ & $9.0(8.8$ to 9.1$)$ & \\
\hline Optic zone & & & $>0.999$ \\
\hline Mean \pm SD & $6.5 \pm 0.0$ & $6.5 \pm 0.0$ & \\
\hline Median (range) & $6.5(6.5$ to 6.5$)$ & $6.5(6.5$ to 6.5$)$ & \\
\hline \multicolumn{4}{|l|}{ Postoperative parameters } \\
\hline Manifest sphere D (D) & & & 0.169 \\
\hline Mean \pm SD & $-1.0 \pm 0.3$ & $-0.02 \pm 0.3$ & \\
\hline Median (range) & $-0.3(-0.5$ to 0.0$)$ & $0(-0.5$ to 0.5$)$ & \\
\hline
\end{tabular}


Table 2. (Continued)

\begin{tabular}{|c|c|c|c|}
\hline Patient demographic & First 20 operations $(n=10)$ & Next 50 operations $(n=26)$ & $p$-value ${ }^{*}$ \\
\hline Cylinder (D) & & & 0.406 \\
\hline Mean \pm SD & $-0.2 \pm 0.3$ & $-0.3 \pm 0.3$ & \\
\hline Median (range) & $-0.3(-0.5$ to 0.3$)$ & $-0.3(-0.8$ to 0.5$)$ & \\
\hline $\mathrm{SE}(\mathrm{D})$ & & & 0.265 \\
\hline Mean \pm SD & $-0.2 \pm 0.3$ & $-0.2 \pm 0.2$ & \\
\hline Median (range) & $-0.3(-0.8$ to 0.4$)$ & $-0.1(-0.8$ to 0.5$)$ & \\
\hline $\mathrm{K} 1(\mathrm{D})$ & & & 0.309 \\
\hline Mean \pm SD & $40.7 \pm 2.6$ & $40.0 \pm 1.6$ & \\
\hline Median (range) & $41.0(36.3$ to 45.8$)$ & $39.6(36.8$ to 43.3$)$ & \\
\hline $\mathrm{K} 2$ (D) & & & 0.326 \\
\hline Mean \pm SD & $41.4 \pm 2.6$ & $40.7 \pm 1.8$ & \\
\hline Median (range) & $41.4(37.0$ to 46.0$)$ & $40.5(37.0$ to 44.0$)$ & \\
\hline Mean keratometry (D) & & & 0.310 \\
\hline Mean \pm SD & $41.1 \pm 2.6$ & $40.3 \pm 1.7$ & \\
\hline Median (range) & $41.2(36.6$ to 45.9$)$ & $40.0(37.0$ to 43.5$)$ & \\
\hline
\end{tabular}

$\mathrm{SD}=$ standard deviation; $\mathrm{D}=$ diopters; $\mathrm{SE}=$ spherical equivalent; $\mathrm{K} 1$ = flat keratometry reading; $\mathrm{K} 2$ = steep keratometry reading. "Mann-Whitney $U$-test; 'Fisher exact test.

square test and Fisher exact test. For comparison of two normally distributed groups Student $t$-test was used. Nonparametric statistical methods were used for values with skewed distribution. For comparison of two nonnormally distributed groups Mann-Whitney $U$-test was used. The chi-square test was used for categorical variables. Data were expressed as mean \pm standard deviation (SD), median (range), and number (\%) where appropriate. A $p$-value of less than 0.05 was considered statistically significant.

\section{Results}

\section{Patient demographics and preoperative and postoper- ative keratometric and aberrometric parameters}

Overall, the mean \pm SD patient age was $26.7 \pm 7.5$ years and female patients composed $50 \%$ of the study population. Patients in the first 20 and next 50 operations were homogenous in terms of age and gender (Table 2). Except for significantly lower preoperative $\mathrm{K} 2$ values in the next 50 operations versus first 20 operations (median [range], 43.9 [42.0-47.8] vs. 45.0 [40.5-49.0]; $p=0.033$ ), no significant difference was noted between study groups in terms of preoperative and postoperative parameters (Table 2).

\section{Comparison of flap thickness related outcome in study groups}

When compared to first 20 operations, next 50 operations were associated with significantly higher values for MCFT (median, $123 \mu \mathrm{m}$ vs. $114 \mu \mathrm{m} ; p=0.007$ ) and MTFT (median, $123 \mu \mathrm{m}$ vs. $113 \mu \mathrm{m}$; $p=0.015$ ), whereas significantly lower intra-FT range (median, $4.0 \mu \mathrm{m}$ vs. $4.5 \mu \mathrm{m}$; $p=0.003$ ). No significant difference was noted between study groups in terms of FTH (Table 3 and Fig. 2).

In the first 20 operations, overall FT was thinner than planned by $-4.6 \mu \mathrm{m}$ (minimum, $110.7 \mu \mathrm{m}$ with a $-9.3 \mu \mathrm{m}$ average difference; maximum, $131.3 \mu \mathrm{m}$ with a $+11.3 \mu \mathrm{m}$ difference) with an average thickness SD of $10.8 \mu \mathrm{m}$. In the next 50 operations, overall FT was thicker than planned by $+3.0 \mu \mathrm{m}$ (minimum, $109.0 \mu \mathrm{m}$ with a $-11.0 \mu \mathrm{m}$ average difference; maximum, $133.7 \mu \mathrm{m}$ with a $+13.7 \mu \mathrm{m}$ difference) with an average thickness SD of $6.6 \mu \mathrm{m}$ (Table 2). Intra-FT range (FT variability) was also significantly lower within the next 50 operations compared to those for the first 20 operations (median, 4.0; range, $1-6$ vs. median, 4.5; range, 3-16; $p=0.003$ ) (Table 3). 
Table 3. Comparison of FT parameters in study groups

\begin{tabular}{|c|c|c|c|c|c|}
\hline \multirow{2}{*}{ Flap outcome } & \multicolumn{2}{|c|}{ First 20 operations $(n=10)$} & \multicolumn{2}{|c|}{ Next 50 operations $(n=26)$} & \multirow{2}{*}{$p$-value } \\
\hline & Mean \pm SD & Median (range) & Mean \pm SD & Median (range) & \\
\hline $\operatorname{MCFT}(\mu \mathrm{m})$ & $114.4 \pm 11.6$ & $114.0(94.0$ to 132.0$)$ & $122.5 \pm 6.6$ & $123.0(109.0$ to 134.0$)$ & $0.007^{*}$ \\
\hline MTFT $(\mu \mathrm{m})$ & $115.4 \pm 10.8$ & $113.0(100.7$ to 131.3$)$ & $123.0 \pm 6.6$ & $123.0(109.0$ to 133.7$)$ & $0.015^{*}$ \\
\hline Intra-FT range $(\mu \mathrm{m})$ & $6.1 \pm 3.6$ & $4.5(3.0$ to 16.0$)$ & $3.5 \pm 1.3$ & $4.0(1.0$ to 6.0$)$ & $0.003^{\dagger}$ \\
\hline FTH $(\mu \mathrm{m})$ & $-3.2 \pm 4.1$ & $-2.5(-16.0$ to 2.0$)$ & $-2.0 \pm 2.3$ & $-2.0(-6.0$ to 2.0$)$ & $0.516^{\dagger}$ \\
\hline
\end{tabular}

FT = flap thickness; SD = standard deviation; MCFT = mean central flap thickness; MTFT = mean total flap thickness; FTH $=$ flap thickness homogeneity.

${ }^{*}$ Student $t$-test; ${ }^{\top}$ Mann-Whitney $U$-test.

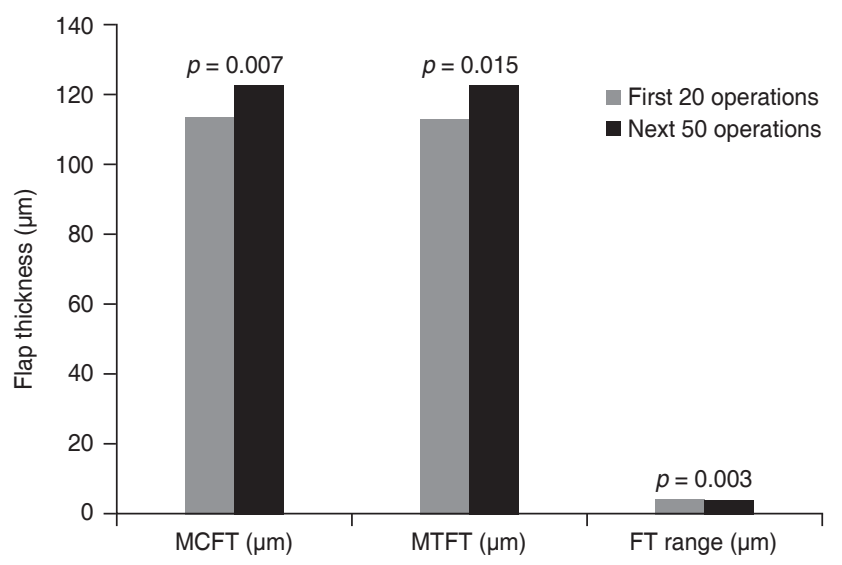

Fig. 2. Comparison of mean central flap thickness (MCFT), mean total flap thickness (MTFT), and intra-flap thickness (FT) range in study groups.

\section{Discussion}

Our findings revealed significant impact of learning curve on FT outcome during FS laser-assisted LASIK surgery with use of new curved applanation cone in terms of achievement of postoperative FT which is closer to the intended thickness along with lower intra-flap range with increase in surgeon's experience. Even though all surgeries were performed by the same surgeon (BSA) who was experienced in FS lasers with planar applanation and FS laser-assisted cataract surgery for 6 years, the patient interface for LenSx laser cataract surgery and LASIK is quite different which requires experience. The aim of this study was to evaluate the impact of learning curve on FT outcome in FS laser-assisted LASIK performed with a new LenSx dual form and new patient interface.

In the current study, as compared with first 20 operations, next 50 operations enabled LenSx flaps that were closer to the intended FT along with lower intra-flap range, suggesting an improving learning curve. This seems notable given that preoperative and postoperative keratometric and aberrometric parameters were homogenous in study groups. While preoperative K2 values were significantly lower in the next 50 eyes than first 20 eyes in our study, no significant association of preoperative keratometry or pachymetry with FT has been previously reported in studies on the accuracy and precision of FT using the FS laser-assisted LASIK $[14,15]$.

According to our experience, in the first 20 operations flaps were thinner than planned by $-4.6 \mu \mathrm{m}$ and SD of FT was $10.8 \mu \mathrm{m}$ (range, -9.3 to $+11.3 \mu \mathrm{m}$ ), whereas in the next 50 operations, flaps were thicker than planned by $+3.0 \mu \mathrm{m}$ and SD of FT was $6.6 \mu \mathrm{m}$ (range, -11.0 to $+13.7 \mu \mathrm{m}$ ). Notably, in the first study to evaluate the visual outcomes and FT accuracy of the LASIK performed with new LenSx multifunctional FS laser system (Alcon Laboratories) by Juhasz et al. [9], the authors reported good visual results and a high FT predictability with the LenSx device when they performed a targeted thick corneal flap of $140 \mu \mathrm{m}$ in all cases. However, they also emphasized that after gaining an initial experience with the device, the FT was set to the current depth of $110 \mu \mathrm{m}$ for use in our everyday clinical practice [9].

The FT predictability with the LenSx device in the current study seems in agreement with the lower SD of flaps created with FS laser ( \pm 5.6 to $\pm 14.5 \mu \mathrm{m}$ ) versus microkeratome (range, \pm 20 to $\pm 40 \mu \mathrm{m}$ ) reported in the past studies [16-19]. The advantage of the FS laser in terms of narrower range of achieved FT versus conventional microkeratomes is considered to translate into few thicker-than-expected flaps and very few thinner flaps, which lowers the risk for ectasia, and both the cap perforation and corneal striae, respectively [15].

Accordingly, our findings seem to suggest a higher pre- 
cision in planar FT creation and thus, better aberrations profile and better mesopic and scotopic visual functions after the first 20 LASIK operations for myopia or myopic astigmatism performed with LenSx FS laser using the new curved applanation cone. This supports the presence of a short learning curve for optimization of the contact surface in LenSx FS laser-assisted myopic LASIK surgery for novice surgeons. Notably, data from a past study among experienced and novice LASIK surgeons indicated a fellowship-training program based on a standardized surgical protocol to result in statistically comparable outcomes between an expert surgeon and a fellowship-trained surgeon when newly transitioned from mechanical microkeratome to a FS laser flap creation [20].

However, it should be noted that, while FS laser-created LASIK flap has been reported to be a uniform flap that may contribute to more predictable refractive and wavefront outcomes [5,9,21], the clinical relevance of FS laser is considered to remain controversial $[5,19]$. In a past study comparing iFS 150-kHz (Abbott Medical Optics, Santa Ana, CA, USA) versus LenSx FS lasers in correction myopia, authors reported association of iFS $150 \mathrm{kHz}$ with significantly lower intra-FT range at every postoperative time point, thus suggesting that this device creates more predictable and more uniform flaps compared with LenSx [5].

In fact, during flap creation using the LenSx platform with a low IOP system with a curved patient interface, the curved interface has been considered likely to make creation of a planar flap more challenging, along with additional potential disadvantages such as the likelihood of the degree of corneal compression to be not uniform depending on the corneal curvature and that of small inadvertent eye movements during suction with a system inducing low IOP elevation to affect FTH [5,11]. Likewise, use of Victus FS laser (Bausch \& Lomb, Rochester, NY, USA), a dual FS laser that similarly to the LenSx system also uses a curved interface and induces low IOP increase, is also considered likely to be not ideal for creation of perfectly planar flaps [11].

However, it should be noted that higher success of FS laser technique in terms of FT predictability has been suggested when set between 110 and $120 \mu \mathrm{m}$ with an SD of 12 $\mu \mathrm{m}$ rather than set between 130 and $140 \mu \mathrm{m}$ with an SD of $18.5 \mu \mathrm{m}$ [22]. Hence, association of FS laser technique with achievement of a comparable FT in thicker flaps $(130 \mu \mathrm{m})$, whereas with a more predictable result in thinner flaps (100 to $110 \mu \mathrm{m})$ has also been noted [23].

Certain limitations to this study should be considered. First, potential lack of generalizability due to relatively small sample size seems an important limitation. Second, short duration of the follow up period seems another limitation which otherwise would extend the knowledge achieved in the current study. Nonetheless, given the scarcity of available studies, providing data on the corneal flap outcome with newly introduced LenSx dual platform using curved applanation cone in FS-assisted LASIK surgery, our findings represent a valuable contribution to the literature.

In conclusion, our findings related to FS laser-assisted LASIK surgery for myopia with new LenSx dual platform using curved applanation cone revealed significant impact of learning curve on the corneal FT outcome in terms of closer FT to the intended value and lower intra-flap range. Thus, our findings emphasize the likelihood of planning and producing more successful LASIK outcomes in terms of consistency and predictability of corneal FT to be attained with increasing surgical experience. The utility of LenSx dual platform with curved applanation cone needs to be further investigated in prospective larger scale long term studies to justify its potential to improve safety and predictability of FS laser-assisted LASIK surgery.

Conflicts of Interest: None.

Acknowledgements: None.

Funding: None.

\section{References}

1. Sugar A, Rapuano CJ, Culbertson WW, et al. Laser in situ keratomileusis for myopia and astigmatism: safety and efficacy: a report by the American Academy of Ophthalmology. Ophthalmology 2002;109:175-87.

2. Varley GA, Huang D, Rapuano CJ, et al. LASIK for hyperopia, hyperopic astigmatism, and mixed astigmatism: a report by the American Academy of Ophthalmology. Ophthalmology 2004;111:1604-17.

3. Huhtala A, Pietila J, Makinen P, Uusitalo H. Femtosecond lasers for laser in situ keratomileusis: a systematic review and meta-analysis. Clin Ophthalmol 2016;10:393-404.

4. Santhiago MR, Smadja D, Gomes BF, et al. Association between the percent tissue altered and post-laser in situ ker- 
atomileusis ectasia in eyes with normal preoperative topography. Am J Ophthalmol 2014;158:87-95.

5. Parafita-Fernandez A, Garcia-Gonzalez M, Katsanos A, et al. Two femtosecond laser LASIK platforms: comparison of evolution of visual acuity, flap thickness, and stromal optical density. Cornea 2019;38:98-104.

6. Pietila J, Huhtala A, Makinen P, Uusitalo H. Flap characteristics, predictability, and safety of the Ziemer FEMTO LDV femtosecond laser with the disposable suction ring for LASIK. Eye (Lond) 2014;28:66-71.

7. Stonecipher K, Ignacio TS, Stonecipher M. Advances in refractive surgery: microkeratome and femtosecond laser flap creation in relation to safety, efficacy, predictability, and biomechanical stability. Curr Opin Ophthalmol 2006;17: 368-72.

8. Farjo AA, Sugar A, Schallhorn SC, et al. Femtosecond lasers for LASIK flap creation: a report by the American Academy of Ophthalmology. Ophthalmology 2013;120:e520.

9. Juhasz E, Filkorn T, Kranitz K, et al. Analysis of planned and postoperatively measured flap thickness after LASIK using the LenSx multifunctional femtosecond laser system. $J$ Refract Surg 2014;30:622-6.

10. Wu BM, Williams GP, Tan A, Mehta JS. A comparison of different operating systems for femtosecond lasers in cataract surgery. J Ophthalmol 2015;2015:616478.

11. Garcia-Gonzalez M, Bouza-Miguens C, Parafita-Fernandez A, et al. Comparison of visual outcomes and flap morphology using 2 femtosecond-laser platforms. J Cataract Refract Surg 2018;44:78-84.

12. Stahl JE, Durrie DS, Schwendeman FJ, Boghossian AJ. Anterior segment OCT analysis of thin IntraLase femtosecond flaps. J Refract Surg 2007;23:555-8.

13. Rocha KM, Randleman JB, Stulting RD. Analysis of microkeratome thin flap architecture using Fourier-domain optical coherence tomography. J Refract Surg 2011;27:75963.

14. Sutton G, Hodge C. Accuracy and precision of LASIK flap thickness using the IntraLase femtosecond laser in 1000 consecutive cases. J Refract Surg 2008;24:802-6.

15. Kim CY, Song JH, Na KS, et al. Factors influencing corneal flap thickness in laser in situ keratomileusis with a femtosecond laser. Korean J Ophthalmol 2011;25:8-14.

16. Arbelaez MC. Nidek MK 2000 microkeratome clinical evaluation. J Refract Surg 2002;18(3 Suppl):S357-60.

17. Shemesh G, Dotan G, Lipshitz I. Predictability of corneal flap thickness in laser in situ keratomileusis using three different microkeratomes. J Refract Surg 2002;18(3 Suppl):S347-51.

18. Kezirian GM, Stonecipher KG. Comparison of the IntraLase femtosecond laser and mechanical keratomes for laser in situ keratomileusis. J Cataract Refract Surg 2004;30: 804-11.

19. Zhang XX, Zhong XW, Wu JS, et al. Corneal flap morphological analysis using anterior segment optical coherence tomography in laser in situ keratomileusis with femtosecond lasers versus mechanical microkeratome. Int $J$ Ophthalmol 2012;5:69-73.

20. Reinstein DZ, Carp GI, Archer TJ, Gobbe M. Transitioning from mechanical microkeratome to femtosecond laser flap creation: visual outcomes of an experienced and a novice LASIK surgeon. J Cataract Refract Surg 2012;38:1788-95.

21. Rosas Salaroli CH, Li Y, Zhang X, et al. Repeatability of laser in situ keratomileusis flap thickness measurement by Fourier-domain optical coherence tomography. J Cataract Refract Surg 2011;37:649-54.

22. Binder PS. Flap dimensions created with the IntraLase FS laser. J Cataract Refract Surg 2004;30:26-32.

23. Garcia-Gonzalez M, Teus MA. Flap thickness in femtosecond laser. J Refract Surg 2015;31:140. 